\title{
Mu Glutathione-S-Transferase Measurement
}

National Cancer Institute

\section{Source}

National Cancer Institute. Mu Glutathione-S-Transferase Measurement. NCI Thesaurus. Code C79457.

The determination of the amount of mu glutathione-s-transferase present in a sample. 